\title{
Plasma free fatty acid in liver disease
}

\author{
A. MORTIAUX ${ }^{1}$ AND A. M. DAWSON \\ From the Medical Unit, Royal Free Hospital, London
}

SYNOPSIS The plasma free fatty acid level was raised in the majority of 131 patients with a variety of liver disorders, and included both those with severe liver cell damage and those with relatively good liver cell function and obstructive jaundice. This raised level is probably due to an increased mobilization of depot fat, for glucose, which inhibits peripheral liberation of free fatty acids, caused a fall in the plasma level and obliteration of the femoral venous-arterial difference in patients with liver disease comparable with that in normal persons. In addition, the plasma free fatty acid flux was measured using palmitate-1-C $\mathbf{C}^{\mathbf{1 4}}$ and was found to be increased in patients with liver disease.

Free or non-esterified fatty acids have only recently been accurately determined in plasma (Davis, 1947; Dole, 1956; Gordon, 1957). Formerly, such acids were often considered to be artefacts of the analytical technique, for they represent only a small fraction (less than $5 \%$ ) of the total fatty acids of the plasma. They provide a major source of energy for the body (Frederickson and Gordon, 1958b). The source of the plasma free fatty acids is mainly adipose tissue where fatty acids are stored in the esterified form as glycerides, and their liberation from adipose tissue into the blood, where they are mainly bound to albumin, is modified by various factors. Broadly speaking, an increased release of free fatty acids, which causes a high plasma level, occurs when the body suddenly needs energy, e.g., in conditions of stress (Dole, 1956; Bogdonoff, Estes, and Trout, 1959), or when utilization of carbohydrate is impaired or decreased, e.g., in uncontrolled diabetes or prolonged starvation (Laurell, 1956; Bierman, Dole, and Roberts, 1957; Albrink and Neuwirth, 1960). Conversely when glucose is given as an alternative source of energy, the liberation of fatty acid is inhibited and the plasma level of free fatty acids falls (Dole, 1956).

Patients with liver disease have an abnormal intermediate carbohydrate metabolism (Amatuzio and Nesbitt, 1950; Dawson, de Groote, Rosenthal, and Sherlock, 1957), and so might theoretically use fat as a major alternative source of energy. Indeed, recently Wajchenberg, Hoxter, Mello, and Ulhoa Cintra (1960) found a raised plasma level of free fatty acids in 18 patients with liver disease.

This paper reports the plasma free fatty acid levels ¿British Council scholar. in a series of 131 patients with a variety of liver disorders. In an attempt to clarify the nature of the disordered metabolism of free fatty acids in liver disease, some observations were made on the effect of parenteral glucose on the plasma level of free fatty acids and its flux was estimated using palmitate$1-C^{14}$.

PATIENTS STUDIED AND METHODS

One hundred and thirty-one patients with liver disease were studied. Twenty-six had alcoholic cirrhosis, 65 had non-alcoholic cirrhosis, of whom 12 were of the juvenile type (Bearn, Kunkel, and Slater, 1956), 14 had primary biliary cirrhosis, four had secondary biliary cirrhosis, nine had extrahepatic biliary obstruction (seven due to a new growth and two to gallstones), five had haemochromatosis but did not require insulin, and eight had viral hepatitis. The only patients who had an associated disorder known to affect metabolism of free fatty acids were those in whom new growth was causing obstructive jaundice (Mueller and Watkin, 1961). The 20 normal control subjects were either medical staff or students.

All subjects had fasted overnight and were resting; the 11 patients attending the out-patient clinic were allowed to rest on a couch for one hour before the blood was taken from an antecubital vein. This was put into a heparin tube and the plasma was separated by centrifuging at $0^{\circ} \mathrm{C}$., usually within 15 minutes but occasionally up to one hour after the blood was taken. The separated plasma was either analysed immediately or after storage for less than four hours in the deep freeze. Dole's method (1956) was used for the free fatty acid determination but Nile blue instead of thymol blue was used as the indicator. The coefficient of variance of 24 determinations on a single plasma was $2.2 \%$. Recovery of palmitic acid added to plasma was $95 \%$.

In 10 patients with hepatic cirrhosis and six normal 
subjects, arterial free fatty acid levels were measured at two 15-minute intervals before, and four 30-minute intervals after, an intravenous injection of glucose $(0.5 \mathrm{~g}$. per kg. body weight). In nine subjects the femoral vein and in seven subjects the antecubital vein free fatty acids were measured simultaneously with the arterial level. Both arterial and venous blood was obtained from an indwelling polythene catheter; heparin was not used to keep the catheter patent.

The fractional turnover rate and flux of plasma free fatty acids were estimated using palmitate-1-C $C^{\mathbf{1 4}}$ (Laurell, 1957; Fredrickson and Gordon, 1958a). This was obtained from the Radiochemical Centre, Amersham, and dissolved in a $0.5 \%$ human albumin solution in physiological saline. The solution was sterilized by passing through a Seitz filter, and the final concentration was approximately $10 \mu \mathrm{c}$. per ml. In eight fasting patients with hepatic cirrhosis who did not have fluid retention and in two subjects without liver disease, $1 \mathrm{ml}$. of the albuminpalmitate-1-C $\mathrm{C}^{14}$ solution was given intravenously and rapid timed samples of blood were obtained from an indwelling polythene arterial catheter during the 11 minutes following the injection. The arterial plasma free fatty acid level was measured chemically at the beginning and end of the procedure and did not alter significantly. All samples were extracted in duplicate by Dole's method, and the free fatty acid in the heptane phase was removed from the other lipid by washing with $50 \%$ alkaline ethanol (Borgström, 1952). The radioactive free fatty acid in the alkaline ethanol was estimated by adding $1 \mathrm{ml}$. aliquots to $10 \mathrm{ml}$. of dioxane which contained a liquid phosphor (Davidson, 1958). It was then counted in an Echo liquid scintillation counter. The plasma volume was measured using $I^{131}$ labelled-albumin, except in three patients with cirrhosis and in one with no liver disease in whom it was estimated according to the method of Caesar, Shaldon, Chiandussi, Guevara, and Sherlock (1961).

\section{FASTING PLASMA FREE FATTY ACID IN LIVER DISEASE}

The normal fasting venous free fatty acid level was $0.52 \pm 0.14 \mathrm{mEq}$. $/ 1$. (mean $\pm 2 \mathrm{SD}$ ) (Fig. 1). The fasting venous levels were above the normal range on 135 of 146 occasions in 131 patients with liver disease (Fig. 1). A similar proportion of high values was observed in all types of liver disease. It made no difference whether the underlying disease affected mainly liver cells, as in cirrhosis and hepatitis, or whether it was associated with jaundice and good liver cell function as in primary biliary cirrhosis. In nine patients with stable liver function, serial readings over a two- to eight-week period were remarkably constant (Fig. 2).

There was no correlation between the plasma free fatty acid level and the serum albumin in 38 randomly-selected patients with cirrhosis (Fig. 3). This is true whether one considers the patients as a

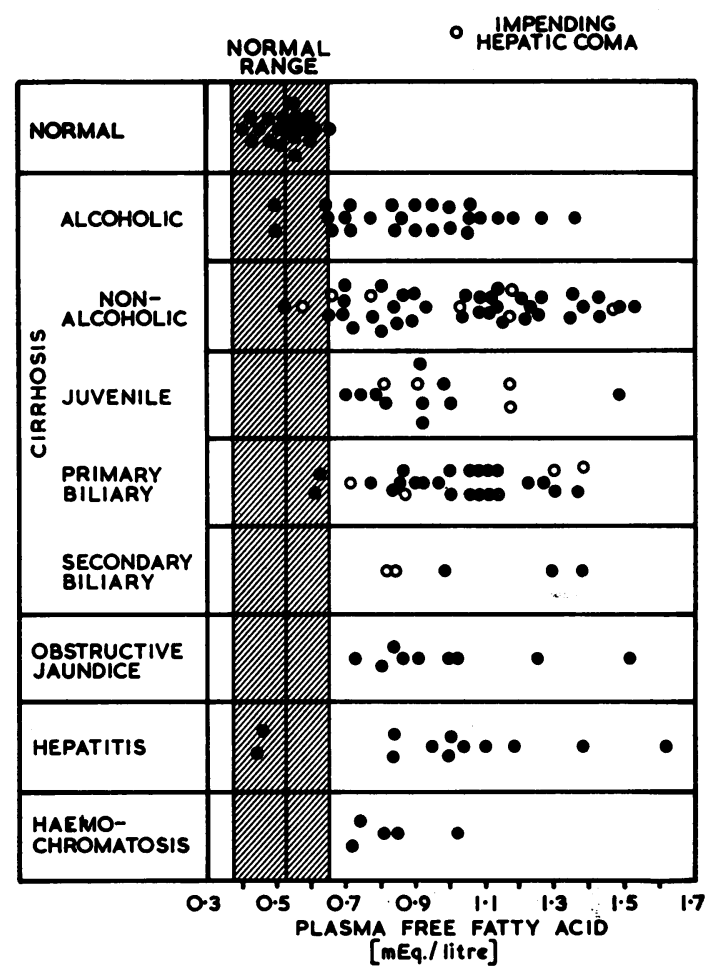

FIG. 1. Fasting plasma free fatty acid levels in patients with liver disease.

The 146 readings were obtained from 131 patients. The mean $\pm 2 S D$ of the normal controls is shown by the shaded area.

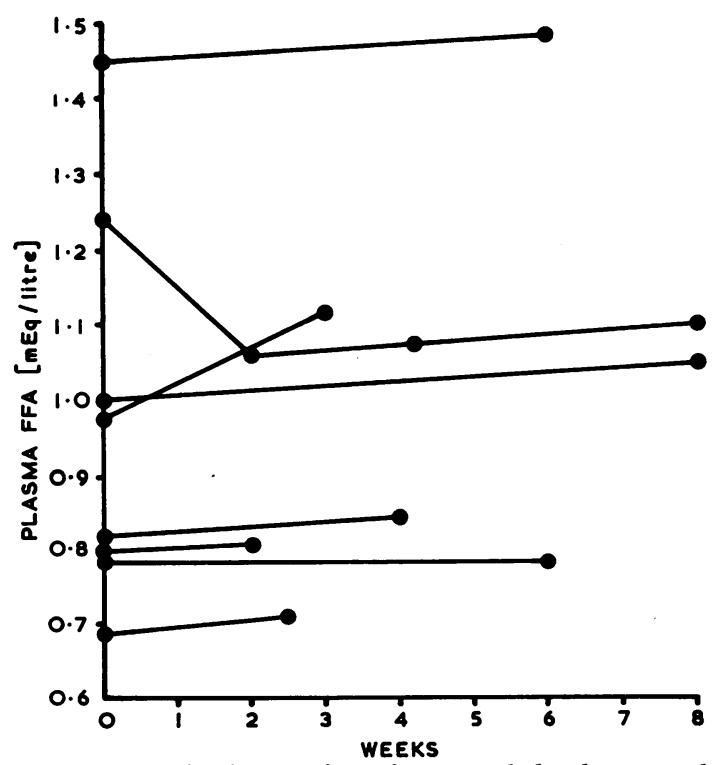

FIG. 2. Serial plasma free fatty acid levels in eight patients with cirrhosis and stable liver cell function. 


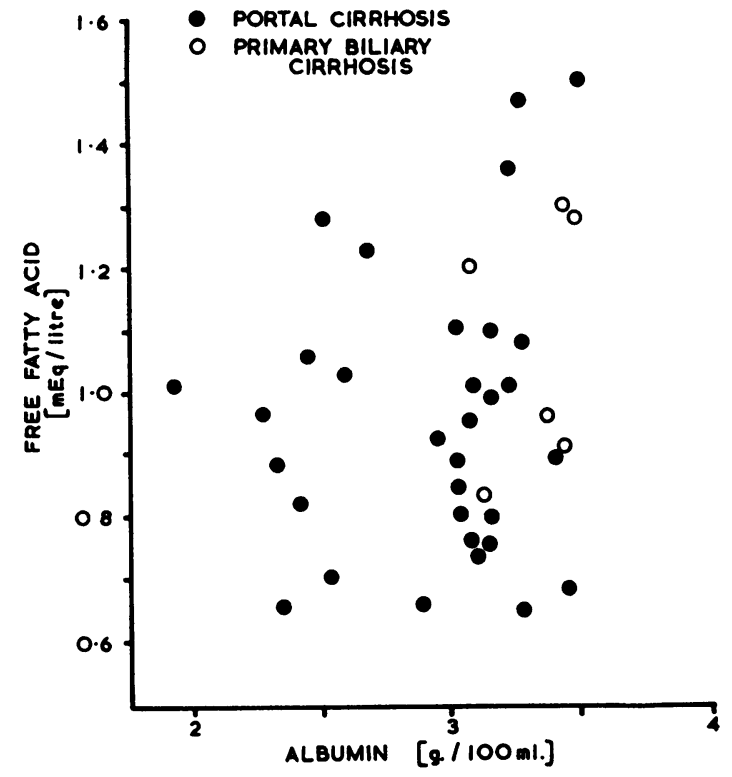

FIG. 3. Plasma free fatty acid level plotted against the serum albumin in 38 patients with cirrhosis.

single group or separates the patients with primary biliary cirrhosis. Similarly, there was no correlation between plasma free fatty acid and the serum bilirubin levels, which varied from 1.2 to $35 \mathrm{mg}$. per $100 \mathrm{ml}$. Patients with impending hepatic coma did not have a higher plasma level than those who were mentally alert ' (Fig. 1).

\section{ORIGIN OF RAISED PLASMA FREE FATTY ACIDS IN LIVER DISEASE}

LIBERATION OF PLASMA FREE FATTY ACIDS IN VITRO The raised plasma free fatty acid levels might have been artefacts due to their liberation in vitro between the time of sampling and analysis. Such hydrolysis of blood in vitro occurs after an injection of heparin

\section{TABLE I}

EFFECT OF STANDING ON PLASMA FREE FATTY ACID LEVEL IN VITRO

\begin{tabular}{lcc} 
Diagnosis & \multicolumn{2}{c}{ Time after Shedding Blood } \\
\cline { 2 - 3 } & 15 min. $(\mathrm{mEq} / \mathrm{l})$. & $60 \mathrm{~min} .(\mathrm{mEq} / \mathrm{l})$ \\
\hline Cirrhosis & 1.17 & 1.13 \\
Cirrhosis & 1.13 & 1.15 \\
Cirrhosis & 1.06 & 1.10 \\
Cirrhosis & 0.99 & 0.98 \\
Cirrhosis & 0.88 & 0.90 \\
Control & 0.66 & 0.66 \\
Control & 0.62 & 0.64 \\
Control & 0.59 & 0.58 \\
Control & 0.56 & 0.59
\end{tabular}

(Rizack, 1960) due to the liberation of lipoprotein lipase into the plasma, and recently Baker, Levine, Turner, and Dubin (1958) found a high liproprotein lipase level in the blood of patients with cirrhosis. To exclude this possibility, on 10 occasions the analysis was performed at 15 minutes and 60 minutes after venepuncture. Free fatty acids were not liberated to a significant extent during this time when the blood had been standing at room temperature (Table I).

\section{THE EFFECT OF INTRAVENOUS GLUCOSE ON PLASMA FREE FATTY ACIDS}

After intravenous glucose, the lowest arterial level in five normal subjects was between 0.25 and 0.4 mEq./l. (Fig. 4). The plasma level of eight of the 10 patients with cirrhosis fell to the same range. The

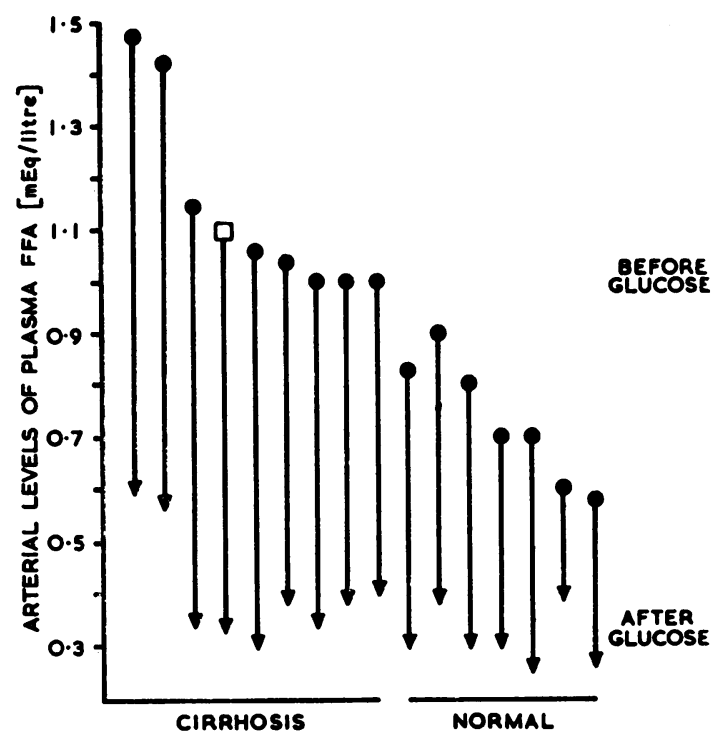

FIG. 4. The effect of intravenous glucose on arterial free fatty acid levels in 10 patients with cirrhosis and six normal subjects. $\square$ Represents a patient with primary biliary cirrhosis.

two patients with the highest fasting level failed to reach this range although they had a greater absolute fall than the normal persons. The slightly raised fasting level in two of the normal subjects was probably due to the stress of arterial puncture (Cardon and Gordon, 1959).

The resting femoral vein arterial free fatty acid difference varied from 0.17 to $0.3 \mathrm{mEq} . / \mathrm{l}$, and the values for the three normal subjects were similar to those of the six patients with liver disease (Fig. 5). After intravenous glucose, the femoral venousarterial difference contracted markedly to between 


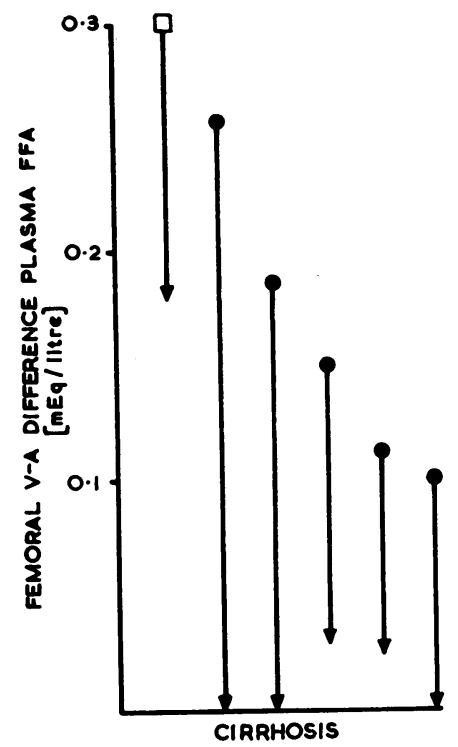

FIG. 5
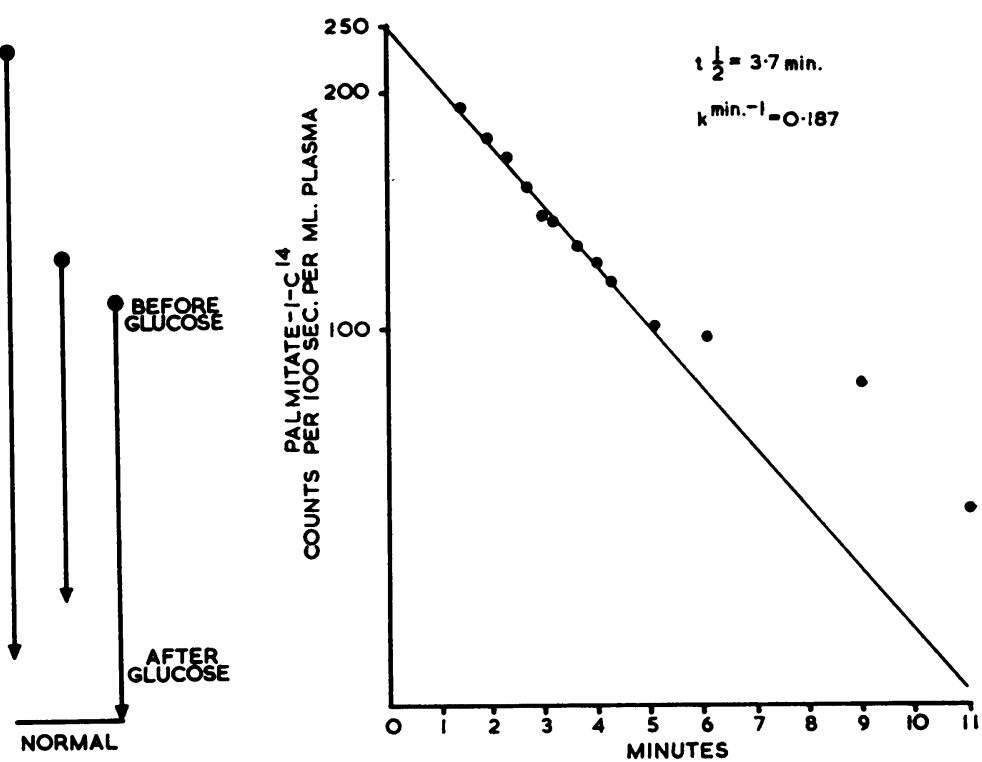

FIG. 6

FIG. 5. The effect of intravenous glucose on the femoral vein-arterial free fatty acid difference in six patients with cirrhosis and three normal subjects. $\square$ Represents a patient with primary biliary cirrhosis.

FIG. 6. The disappearance of palmitate-l-C $C^{14}$ from the plasma in a patient with cirrhosis, fasted for 12 hours.

0 and $0.05 \mathrm{mEq} . / 1$. in the three normal persons and in the five patients with portal cirrhosis; the patient with primary biliary cirrhosis had a less impressive contraction to $0.18 \mathrm{mEq}$./litre.

The fasting antecubital venous-arterial difference was minimal, being less than $0.01 \mathrm{mEq} . / 1$. in three normal persons and in four patients with liver diseases: this might be expected, for the antecubital vein drains the forearm, which is mainly lean tissue.

\section{PALMITATE-L-C ${ }^{14}$ TURNOVER}

After injection there is a rapid exponential fall in concentration of plasma palmitate-l- $\mathrm{C}^{14}$ for the first two to five minutes; the disappearance then becomes more complex. The half-time of this initial fall was measured, and from this the rate constant $\left(\mathrm{K}=0.693 / \mathrm{t}_{\mathrm{2}}\right)$ was calculated and represents the fraction of the plasma free fatty acids which dis-

TABLE II

PLASMA FREE FATTY ACID FLUX IN LIVER DISEASE

\begin{tabular}{|c|c|c|c|c|c|c|c|c|}
\hline Diagnosis & $\begin{array}{l}\text { Weight } \\
\text { (kg.) }\end{array}$ & $\begin{array}{l}T_{\frac{1}{2}} \\
\text { (min.) }\end{array}$ & $\begin{array}{l}K \\
\left(\min .^{-1}\right)\end{array}$ & $\begin{array}{l}\text { Total Plasma } \\
\text { Volume } \\
(\mathrm{ml} .)\end{array}$ & $\begin{array}{l}\text { Plasma } \\
\text { FFA } \\
(m E q . / l .)\end{array}$ & $\begin{array}{l}\text { Total Circu- } \\
\text { lating FFA } \\
\text { (mEq.) }\end{array}$ & $\begin{array}{l}\text { Plasma } \\
\text { FFA Flux } \\
\text { (mEq./min.) }\end{array}$ & $\begin{array}{l}\text { Plasma FFA } \\
\text { Flux per Kg. } \\
\text { Body Weight } \\
(\text { mEq./min./kg. }) \\
\left(\times 10^{-6}\right)\end{array}$ \\
\hline $\begin{array}{l}\text { Cirrhosis } \\
\text { Cirrhosis } \\
\text { Cirrhosis } \\
\text { Cirrhosis } \\
\text { Cirrhosis } \\
\text { Cirrhosis } \\
\text { Cirrhosis } \\
\text { Cirrhosis } \\
\text { Mean }\end{array}$ & $\begin{array}{l}69 \\
76 \\
57 \cdot 5 \\
65 \cdot 6 \\
64 \\
47 \\
41 \cdot 8 \\
64 \cdot 5 \\
60 \cdot 9\end{array}$ & $\begin{array}{l}3 \cdot 7 \\
1.95 \\
2 \cdot 45 \\
2 \cdot 55 \\
2 \cdot 50 \\
3 \cdot 8 \\
2 \cdot 1 \\
2 \cdot 1 \\
2 \cdot 6\end{array}$ & $\begin{array}{l}0.19 \\
0.35 \\
0.28 \\
0.27 \\
0.28 \\
0.18 \\
0.33 \\
0.33 \\
0.27\end{array}$ & $\begin{array}{l}3,919 \\
3,952^{1} \\
3,500 \\
3,411^{1} \\
4,440 \\
3,640 \\
2,176^{1} \\
3,590 \\
3,578\end{array}$ & $\begin{array}{l}1 \cdot 100 \\
1.060 \\
1 \cdot 300 \\
0.950 \\
1 \cdot 160 \\
1 \cdot 333 \\
1.082 \\
1 \cdot 155 \\
1 \cdot 142\end{array}$ & $\begin{array}{l}4 \cdot 311 \\
4 \cdot 189 \\
4 \cdot 550 \\
3 \cdot 240 \\
5 \cdot 150 \\
4 \cdot 852 \\
2 \cdot 354 \\
4 \cdot 146 \\
4 \cdot 099\end{array}$ & $\begin{array}{l}0.81 \\
1.46 \\
1.27 \\
0.87 \\
1.44 \\
0.88 \\
0.77 \\
1.37 \\
1.11\end{array}$ & $\begin{array}{l}117 \\
193 \\
221 \\
134 \\
225 \\
187 \\
185 \\
213 \\
184\end{array}$ \\
\hline $\begin{array}{l}\text { Control } \\
\text { Control } \\
\text { Mean }\end{array}$ & $\begin{array}{l}81 \\
83 \cdot 7 \\
82 \cdot 4\end{array}$ & $\begin{array}{l}2 \cdot 34 \\
1 \cdot 9 \\
2 \cdot 1\end{array}$ & $\begin{array}{l}0.30 \\
0 \cdot 36 \\
0.33\end{array}$ & $\begin{array}{l}3,760 \\
3,385^{1} \\
3,572\end{array}$ & $\begin{array}{l}0.680 \\
0.600 \\
0.640\end{array}$ & $\begin{array}{l}2 \cdot 556 \\
2 \cdot 031 \\
2 \cdot 293\end{array}$ & $\begin{array}{l}0.77 \\
0.73 \\
0.75\end{array}$ & $\begin{array}{l}95 \\
87 \\
92\end{array}$ \\
\hline
\end{tabular}

'Calculated according to Caesar et al. (1961). 
appears each minute. When $\mathrm{K}$ is multiplied by the total plasma free fatty acid, which is obtained by multiplying the plasma volume by the plasma free fatty acid, the result equals the flux or the amount of plasma free fatty acid disappearing each minute. The results of such estimations in eight patients with portal cirrhosis and in two normal persons are shown in Table II. The mean plasma flux was 0.75 $\mathrm{mEq}$./min. for the two persons without liver disease. This is comparable to the estimation of Fredrickson and Gordon (1958a) who calculated a mean flux of $0.66 \mathrm{mEq} . / \mathrm{min}$. in 18 normal persons after an overnight fast. The eight patients with cirrhosis all had a high plasma free fatty acid flux (0.81 to $1.44 \mathrm{mEq}$./ min.) with a mean of $1.06 \mathrm{mEq} . / \mathrm{min}$. The difference between the two groups is even more impressive if a correction is made for body weight, as the patients with cirrhosis were not as heavy as the controls (Table II).

As an excess of adrenaline is a common cause of a raised plasma free fatty acid level, the urinary excretion of the main metabolite of adrenaline, 3 methoxy 4 hydroxymandelic acid (VMA), was measured in two patients with portal cirrhosis and two with primary biliary cirrhosis who had a plasma free fatty acid level of over $1 \mathrm{mEq}$./litre. This was normal.

\section{DISCUSSION}

In this study, the normal range of fasting antecubital venous free fatty acid measured by Dole's method was similar to that previously reported (Munkner, 1959; Wajchenberg et al., 1960; Corvilain, Loeb, Champenois, and Abramow, 1961). The almost invariably raised plasma free fatty acid level in patients with all types of liver disease amplifies the observations of Wajchenberg et al. (1960) who found such raised plasma levels in 18 patients with hepatocellular disease. In the present series patients with obstructive jaundice and minimal hepatocellular damage also had a high level, although in some of these patients the underlying neoplastic disease might have contributed to it (Mueller and Watkin, 1961). It was surprising that there was no apparent correlation between plasma free fatty acid levels and the degree of liver cell failure, the depth of jaundice or the presence of neuropsychiatric complications. It might be that serial observations on a single patient with a fluctuating clinical course would be more valuable than comparing groups of patients with different clinical states. Our serial observations were on patients with stable liver function, and the plasma free fatty acid levels were remarkably steady. These observations differ from those of Stormont and Mackie (1959) who found a raised plasma free fatty acid level mainly in patients with severe hepatocellular failure, especially when hepatic coma was present. These differences might be explained by the fact that their normal range was much higher than ours $(0.76 \pm 0.04 \mathrm{mEq}$. $/ \mathrm{l}$, mean $\pm \mathrm{SE})$ and that most of their patients probably, in addition to liver disease, had metabolic disorders associated with alcoholism.

Dole's method partially estimates short chain organic acids in addition to plasma free fatty acids. These include pyruvic acid and $\alpha$ ketoglutamic acid, which are raised in the plasma of patients with liver disease (Dawson et al., 1957). The results of the intravenous glucose test discount the suggestion that the raised levels are due to an increase in short chain acids, for after glucose the plasma level of such acids rise or remain constant (Amatuzio, Shrifter, Stutzman, and Nesbitt, 1952) while the true plasma free fatty acid level falls, as was observed in our patients.

A raised plasma level may, theoretically, be due to an increased mobilization of peripheral fat, to diminished utilization of free fatty acids, or to hydrolysis of esterified fat in the blood stream. Hydrolysis of esterified fat in blood did not continue in vitro after the blood was drawn, and this cause is unlikely. Raised plasma levels in various clinical situations such as prolonged starvation, diabetes, thyrotoxicosis, and 'stress' are thought to be mainly due to increased mobilization of tissue fat, though often the evidence for this has been indirect. If the high plasma free fatty acid level were due to decreased utilization, suppression of the peripheral release of free fatty acids would be followed by a less impressive fall in the arterial level in the affected group than in the controls. Conversely, if the raised levels were due to an increased mobilization of tissue fat, an inhibition of this process would be followed by a rapid fall in arterial free fatty acid levels which would be equal to or greater than the controls. Glucose inhibits the release of free fatty acids from adipose tissue both in vitro (Raben and Hollenberg, 1960) and in vivo as shown by the obliteration of the femoral venous-arterial free fatty acid difference (Gordon, 1957). The similar response to intravenous glucose of our patients and normal persons, both with respect to the obliteration of the femoral venousarterial difference and the associated fall of plasma free fatty acids, suggests that the increased level is not due to impaired utilization of plasma free fatty acids. More direct evidence for the cause of the raised plasma level is given by the palmitate-1- $\mathrm{C}^{\mathbf{1 4}}$ studies. During these studies the plasma free fatty acid levels remained constant and so the increased flux of palmitate-1- $\mathrm{C}^{\mathbf{1 4}}$ in patients with liver disease means an increased production as well as removal of 
plasma free fatty acids. The assumptions in such calculations have been discussed by Laurell (1957) and by Frederickson and Gordon (1958a). The calculated plasma free fatty acid flux in these patients was comparable to that observed in a patient after prolonged starvation (Laurell, 1957) when the body is mainly dependent upon fat as a source of energy.

Not all free fatty acids which are removed from the plasma are immediately oxidized, and the balance is re-esterified in the liver before being transported by the blood back to peripheral tissues for storage (Frederickson and Gordon, 1958b). When excessive, this may contribute to the formation of a fatty liver and a raised blood glyceride level. Such a raised level has only been reported in obstructive jaundice (Phillips, 1960) and not in portal cirrhosis (Wajchenberg et al., 1960). The mechanism for the increased mobilization of tissue fat remains undetermined. It seems unlikely that adrenaline, which so frequently causes this phenomenon, can be implemented, for the urinary excretion of its main metabolite (VMA) was normal in four patients with a liver disorder and raised plasma levels of free fatty acids.

We wish to thank Professor J. Caroli, who allowed us to study some of his patients with alcoholic cirrhosis, and also Dr. Merton Sandler, who performed the V.M.A. estimations.

We would also like to thank the Prudential Life Assurance Company for financial help.

\section{REFERENCES}

Albrink, M. J., and Neuwirth, R. S. (1960). Effect of previous starvation on the response of plasma lipids and free fatty acids to a fat meal. J. clin. Invest., 39, 441-446.

Amatuzio, D. S., and Nesbitt, S. (1950). A study of pyruvic acid in the blood and spinal fluid of patients with liver disease with and without hepatic coma. Ibid., 29, 1486-1490.

-, Shrifter, N., Stutzman, F. L., and Nesbitt, S. (1952). Blood pyruvic acid response to intravenous glucose or insulin in the normal and in patients with liver disease and with diabetes mellitus. Ibid., 31, 751-755.

Baker, S. P., Levine, H., Turner, L., and Dubin, A. (1958). Lipoprotein lipase response in Laennec's cirrhosis. Proc. Soc. exp. Biol. (New York), 99, 670-672.

Bearn, A. G., Kunkel, H. G., and Slater, R. J. (1956). The problem of chronic liver disease in young women. Amer. J. Med., 21, 3-15.
Bierman, E. L., Dole, V. P., and Roberts, T. N. (1957). An abnormality of nonesterified fatty acid metabolism in diabetes mellitus. Diabetes, 6, 475-479.

Bogdonoff, M. D., Estes, E. H., and Trout, D. (1959). Acute effect of psychological stimuli upon plasma non-esterified fatty acid level. Proc. Soc. exp. Biol. (New York), 100, 503-504.

Borgström, B. (1952). Investigation on lipid separation methods. Acta physiol scand., 25, 111-119.

Caesar, J., Shaldon, S., Chiandussi, L., Guevara, L., and Sherlock, S. (1961). The use of indocyanine green in the measurement of hepatic blood flow and as a test of hepatic function. Clin. Sci, 21, 43-57.

Cardon, P. V., and Gordon, R. S. (1959). Rapid increase of plasma unesterified fatty acids in man during fear. J. Psychosom. Res. 4, 5-9.

Corvilain, J., Loeb, H., Champenois, A., and Abramow, M. (1961). Effect of fasting on levels of plasma-nonesterified fatty acids in normal children, normal adults, and obese adults. Lancet, 1, 534-535.

Davidson, J. D. (1958). In Liquid Scintillation Counting, pp. 88-95. Eds. Bell, C. G. and Hayes, F. Newton. Pergamon Press, London.

Davis, B. D. (1947). The estimation of small amounts of fatty acid in the presence of polyoxyethylene sorbitan partial fatty acid esters ("Tween") and of serum proteins. Arch. Biochem., 15, 351-358.

Dawson, A. M., de Groote, J., Rosenthal, W. S., and Sherlock, S. (1957). Blood pyruvic-acid and alpha-ketoglutaric-acid levels in liver disease and hepatic coma. Lancet, 1, 392-396.

Dole, V. P. (1956). A relation between non-esterified fatty acids in plasma and the metabolism of glucose. J. clin. Invest., 35, 150-154.

Fredrickson, D. S., and Gordon, R. S. (1958a). The metabolism of albumin-bound $\mathrm{C}^{16}$-labelled unesterified fatty acids in normal human subjects. Physiol Rev., 37, 1504-1515.

,$--(1958 \mathrm{~b})$. Transport of fatty acids. Ibid., 38, 585-630.

Gordon, R. S. (1957). Unesterified fatty acid in human blood plasma. II. The transport function of unesterified fatty acid. J. clin. Invest., 36, 810-815.

Laurell, S. (1956). Plasma free fatty acids in diabetic acidosis and starvation. Scand. J. clin. Lab. Invest., 8, 81-82.

(1957). Turnover rate of unesterified fatty acids in human plasma. Acta Physiol. scand., 41, 158-167.

Mueller, P. S., and Watkin, D. M. (1961). Plasma unesterified fatty acid concentrations in neoplastic disease. J. Lab. clin. Med., 57, 95-108.

Munkner, C. (1959). Fasting concentrations of non-esterified fatty acids in diabetic and non-diabetic plasma and diurnal variations in normal subjects. Scand. J. Lab. clin. Invest., 11, 388-393.

Phillips, G. B. (1960). The lipid composition of serum in patients with liver disease. J. clin. Invest., 39, 1639-1650.

Raben, M. S., and Hollenberg, C. H. (1960). Effect of glucose and insulin on the esterification of fatty acids by isolated adipose tissue. Ibid., 39, 435-439.

Rizack, M. A. (1960). Intravascular effect of heparin on plasma nonesterified fatty acid and triglyceride during alimentary lipemia. Proc. Soc. exp. Biol. (New York), 104, 111-113.

Stormont, J. M., and Mackie, J. E. (1959). An abnormality of nonesterified fatty acid metabolism in alcoholic patients with cirrhosis. J. clin. Invest., 38, 1047 (Abs.).

Wajchenberg, B. L., Hoxter, G., Mello, E. H. L., and Ulhoa Cintra, A. B. (1960). Non-esterified and esterified fatty acids in hepatocellular disease. Lancet, 1, 1218-1219. 